annually. Only a few months ago the international cosmetics firms Avon and Revlon announced that they had found ways to ensure the safety of their products without animal experimentation. This was a response to years of pressure from the animal liberation group. It will save thousands of animals every year from painful, often lethal, tests. ${ }^{2}$

Opposition to animal experimentation shows every sign of being with us for many years to come, since its philosophical foundation is clear and difficult to gainsay. Among scientists in the United States, where standards of regulation for animal experimentation lag far behind even those in Britain, there are signs of a reflex defensiveness which can lead only to polarisation and increasing hostility between experimenters and the animal liberation movement. ${ }^{3}$ Doctors and scientists in Britain should resist this tendency to overrespond. Instead they should look for ways in which they can make a radical break with a past in which animal experimentation has been accepted with far too little questioning.

Director,

PETER SINGER

Centre for Human Bioethics,

Monash University, Melbourne,

Victoria 3168, Australia

1 Home Office. Statistics of scientific procedures on living animals. London, HMSO, 1988. (Cmnd 743)

2 Gill L. Beauty and the beasts. The Times $1989 \mathrm{Jul} \mathrm{5,} \mathrm{p15,} \mathrm{cols} \mathrm{7-8.}$

3 Council on Scientific Affairs. Animals in research. FAMA 1989;261:3602-6.

\title{
Treatment of persistent pain
}

\section{Behavioural methods give good results}

Patients with persistent benign pain present a problem for all clinicians from whom they seek help. The biomedical model of illness encourages doctors to believe that where there is pain there is a pathological lesion and that if we probe enough we will find it. ${ }^{1}$ Treating the disorder will then cure the pain. The problem with patients with persistent pain is that either we cannot find a lesion to treat or we have no treatment for a known lesion. Do behavioural approaches have anything to offer these unfortunate patients?

The behaviourist would suggest that this model of illness is inappropriate in chronic pain, which is best viewed as a complex of dysfunctions-neurophysiological, emotional, and social - with associated changes in behaviour. ${ }^{23}$ Patients show features such as depression, sleeplessness, inactivity, unfitness, excessive consumption of drugs, pain behaviour, and cognitive dysfunction, which though secondary to the pain form a symptom complex similar wherever its site. This pattern has been labelled the chronic pain syndrome. ${ }^{4}$

Fordyce was the first to treat such patients in a behavioural setting. He argued that many of these dysfunctions could be seen as learned maladaptive behaviours and could be changed, as can any behaviour, if the contingencies of the behaviour are altered. ${ }^{5} \mathrm{He}$ showed that by using "operant conditioning" patients' pain behaviour could indeed be abolished and their functions improved. ${ }^{67}$ Subsequent work has developed this approach, adding cognitive elements, and today most American pain clinics offer behavioural techniques. Treatment may vary from a few outpatient sessions to a stay of several weeks in an inpatient unit. The programmes are usually run by psychologists and staffed by a multidisciplinary team including physiotherapists, nurses, and occupational therapists.

Are such programmes the solution of our patients with chronic pain? The first point that has to be made is that such approaches do not "cure" the pain, nor do they attempt to, and thus to use this as a yardstick of their success is inappropriate. They do aim to restore patients to normal function in spite of the pain, and the gains in this area can be remarkable and extremely gratifying for both the patient and therapist. Published reports have come mostly from the United States for patients with low back pain; these suggest that $60-70 \%$ of patients will make changes..$^{8-11}$ In particular, patients increase their activity, ${ }^{12-1+}$ have fewer pain behaviours, ${ }^{15}$ require fewer drugs, ${ }^{71617}$ are able to return to work, ${ }^{18}$ and make less future use of health care facilities. ${ }^{19} 20$ Depressive symptoms may be strikingly improved, ${ }^{21}$ and the intensity of the pain may be reduced. ${ }^{12}{ }^{17} 19$ Long term follow up suggests that the changes are maintained. ${ }^{12} 1+22$

Though some of the early data were poor, ${ }^{9}$ more recent studies have been better designed and controlled and have longer follow up..$^{23}$ Many questions have still to be answered, however; the type of patient and pain most suited, the components of the treatment responsible for the changes, and whether inpatient programmes are superior to outpatient programmes. Inpatient programmes in the United States may cost up to $\$ 25000$ per patient, but they are usually funded by workers' compensation schemes on the basis that the treatment is effective and economically sound.

Doctors in Britain could be forgiven for knowing little about such approaches because there are few programmes in this country and few outcome data. ${ }^{2+}$ This does not reflect lack of suitable patients, of whom there are an alarming number, but rather ignorance of the approach and lack of the resource. Interest is increasing, however, with various pain clinics starting outpatient groups and reporting results ${ }^{25}$ and the grant funded inpatient unit at St Thomas's receiving an ever increasing number of referrals.

Patients with chronic pain suffer greatly and are avid and often inappropriate users of health care resources. Behavioural treatment can make economic and humanitarian sense.

C E PITHER

Medical Director INPUT,

St Thomas's Pain Management Centre,

St Thomas's Hospital,

London SE1 7EH

\footnotetext{
1 Engel GL. The need for a new medical model: a challenge for biomedicine. Science 1977;196: 129-36.

2 Turk DC, Meichenbaum D, Genest M. Pain and behavioural medicine: a cognitive behavioural perspective. New York: Guildford, 1983.

Sanders SH. A trimodal conceptualisation of clinical pain. Percept Mot Skills 1979:48:551-5.

4 Pinsky JJ. Chronic intractable benign pain: a syndrome and its treatment with intensive short-term group psychotherapy. I Human Stress 1978;4:17-21.

group psychotherapy. I Human Stress 1978;4:17-21.
Fordyce WE. Behavioural methods for chronic pain and illness. St Louis: Mosby, 1976.

5 Fordyce WE. Behavioural methods for chronic pain and illness. St Louis: Mosby, 1976. ordyce WE, Fowler R, Lehman J, DeLateu
chronic pain. f Chronic Dis 1968;21:179-90.

7 Fordyce WE, Fowler R, Lehman J, DeLateur B, Sand P, Treischman R. Operant conditioning in the treatment of chronic pain. Arch Phys Med Rehabil 1973;54:399-408.

Turner JA, Chapman CR. Psychological interventions for chronic pain: a critical review. Pain 1982;13:23-46.

Linton SJ. A critical review of behavioural treatments for chronic benign pain other than headache. Br f Clin Psychol 1982;21:321-37.

10 Aronoff GM, Evans WO, Enders PL. A review of follow up studies of multidisciplinary pain units. Pain 1983;16:1-11.

11 Keefe FT, Gil KM, Rose SC. Behavioural approaches in the multidisciplinary management of chronic pain: programmes and issues. Clin Psych Rev 1986;6:87-113.

2 Chapman SL, Brena SF, Bradford LA. Treatment outcome in a chronic pain rehabilitation program. Pain 1981;11:255-68.

program. Pain 1981;11:255-68.
3 Swanson D, Swenson W, Maruta T, McPhee M. Program for managing chronic pain. Mavo Clin Proc 1976:51:401-11.
} 
14 Roberts AH, Reinhardt L. The behavioural management of chronic pain: long term follow up with comparison groups. Pain 1980;8:151-62.

Cinciripini PM, Floreen A. An evaluation of a behavioural program for chronic pain. $f$ Behav Med 1982:5:375-89.

16 Keefe FJ, Block AR, Williams RB, Surwit RJ. Behavioral treatment outcome of chronic low back pain: clinical outcome and individual differences in pain relief. Pain 1981;11:221-31.

17 Ignelzi R, Sternbach R, Timmermans G. The pain ward follow up analysis. Pain 1977:3: 277-80

18 Gottlieb HJ, Koller R, Alperson BR. Low back pain comprehensive rehabilitation program: follow up study. Arch Phys Med Rehabil 1982;63:458-60.

19 Painter JR, Seres JL, Newman RI. Assessing benefits of the pain centre: why some patients regress. Pain 1980;8:101-13.
20 Cairns R, Thomas L, Mooney Y, Pace J. A comprehensive treatment approach to chronic low back pain. Pain 1976:2:301-8

21 Maruta T, Yatterot $M \mathrm{~K}$, McHardy $\mathrm{MJ}$. Pain management as an antidepressant: long term resolution of pain associated depression. Pain 1989;36:335-7.

22 Guck TP, Skultety FM, Meilman PW, Dowd ET. Multidisciplinary pain centre follow up with a no-treatment control group. Pain 1985;21:295-306.

23 Linton SJ. Behavioural remediation of chronic pain: a status report. Pain 1986;24:125-41.

24 Fisher $\mathrm{K}$. Early experience of a multidisciplinary pain management programme. Holistic Med 1988;3:47-56.

25 Skinner J, Pearce SJ, Erskine A, Robinson I. An outpatient pain management programme. $f$ Psychosom Res (in press).

\title{
Is sudden infant death syndrome a diagnosis?
}

\author{
Or is it just a diagnostic dustbin?
}

As infant mortality diminished in the first half of this century more attention was given to those babies dying unexpectedly and with less florid disease. The skills required to study such deaths had not, however, been developed, and the result was that diagnoses ranged from "pneumonitis" to "suffocation." The latter label led to parents being interrogated by the police and to social stigma. In 1969 a group in Seattle, believing that all of these were natural deaths, recommended that they should be registered as the sudden infant death syndrome. ${ }^{1}$ This approach was rapidly copied throughout the world.

The diagnosis was seductive for five reasons. First of all, it enabled doctors to tell parents that their child had died of natural causes and that no one could have prevented it. It excused all concerned from any defect in care, diagnosis, and treatment. Pathologists welcomed the diagnosis: the less they found, the more certain they could be. Because the syndrome was of unknown origin health authorities had no basis for prevention. And finally, this diagnosis facilitated the development of parent support groups and the raising of money for research. Those concerned in research and support became media sensitive, and all concerned looked for the day when a genius would find "the cause."

This, then, is the setting in which armchair theories surface monthly. Yet, as the diagnosis is open, parents relate every new theory to themselves. If it concerns some obscure reflex, brain enzyme, or organism they are content, but any theory that reflects on the care of their child makes them feel threatened. They react, and they are supported by doctors who have developed an interest in their welfare.

At the XIX International Congress of Paediatrics in Paris in 1989 we were told that these deaths are increasing in Sweden (S G Norvenius) and Finland (P Rintahaka). The same has been occurring in New Zealand ${ }^{2}$ and in some districts in Britain. ${ }^{3}$ One British group (E M Taylor) reported that only $17 \%$ of deaths diagnosed as the sudden infant death syndrome were completely unexplained. A Paris group concurred, describing seven of 45 as unexplained. ${ }^{+}$The diagnosis depends on necropsy findings, but in Holland only half the infants so described have necropsies (J Huber, personal communication) and in France the proportion is only a third (C Nezelof, personal communication). In Britain it is over $90 \%$.

Questions are now beginning to be asked, including: Is there such an entity as the sudden infant death syndrome or is it a convenient diagnostic dustbin? If, as has been alleged, $5-10 \%$ of sudden infant deaths are infanticide is the label the sudden infant death syndrome facilitiating infanticide? The justification for retaining the sudden infant death syndrome is the supposed benefit to parents, but who is benefiting - the doctors or the parents? The "no cause, no guilt" approach has never been subjected to any controlled trial; nor is there any evidence that a parent of a victim of cot death has greater need for help than one given a diagnosis of meningitis or of "cause unknown." To abolish the sudden infant death syndrome as a registerable cause of death would simply put the clock back to 1960. Among research workers there is much vested interest against change. Lip service is paid to possible multiple causes, but each acts as if his or her own theory is universal.

The speakers in Paris concluded that all postperinatal deaths should be examined in very great depth in a few centres that have the time and skill to do so; epidemiological studies should be based only on data from these centres; and journals should be encouraged to accept only those studies on the sudden infant death syndrome in which every child has been examined by a paediatric pathologist and been subject to a neutral confidential inquiry. What else can we do?

Emeritus Professor of Paediatric Pathology,

JOHN L EMERY

University of Sheffield

Sheffield S10 3BN

\footnotetext{
1 Bergman AB, Beckwith JB, Ray CC. Sudden infant death syndrome. Seattle: University of Washington Press, 1970.

Hassall IB. Sudden infant death syndrome-a serious New Zealand health problem. $N$ Z Med $\mathcal{J}$ 1986;99:233-4.

3 Taylor EM, Emery JL. Trends in unexpected infant deaths in Sheffield. Lancet 1988;ii:1121-3.

4 Dehan M, Imbert MC, Gautier JP, et al. Clinical and pathological analysis of 59 consecutive cases of sudden unexpected deaths in infants. Arch Fr Pediatr 1988:45:541-8.
} 